\title{
Molecular characterization of the surface of apoptotic neutrophils: Implications for functional downregulation and recognition by phagocytes
}

\author{
SP Hart ${ }^{1}$, JA Ross ${ }^{2}, \mathrm{~K}_{\text {Ross }}{ }^{1}$, C Haslett ${ }^{1}$ and I Dransfield ${ }^{\star, 1}$ \\ 1 The Rayne Laboratory, Respiratory Medicine Unit, University of Edinburgh \\ Medical School, Teviot Place, Edinburgh, EH8 9AG, UK \\ 2 Edinburgh University Department of Surgery, Royal Infirmary, Lauriston Place, \\ Edinburgh, UK \\ * Correspondence to Dr I Dransfield, The Rayne Laboratory, Respiratory \\ Medicine Unit, University of Edinburgh Medical School, Teviot Place, \\ Edinburgh, EH8 9AG, UK. Tel: 44-131 650 6948; Fax: 44-131 650 4384; \\ E-mail: i.dransfield@ed.ac.uk
}

Received 22.9.99; revised 14.2.00; accepted 15.2.00

Edited by M Piacentini

\begin{abstract}
We have used a panel of monoclonal antibodies and lectins to examine the profile of surface molecule expression on human neutrophils that have undergone spontaneous apoptosis during in vitro culture. Neutrophil apoptosis was found to be accompanied by down-regulation of the immunoglobulin superfamily members PECAM-1 (CD31), ICAM-3 (CD50), CD66acde, and CD66b and the integrin-associated proteins CD63 and urokinase plasminogen activator receptor (CD87) that may alter the potential for adhesive interactions. Cellular interactions may be further influenced by the reduction of the expression of surface carbohydrate moieties, including sialic acid. Reduced expression of Fc $\gamma$ RII (CD32), complement receptor type 1 (CD35) and receptors for pro-inflammatory mediators C5a (CD88) and TNF $\alpha$ (CD120b) associated with apoptosis might limit neutrophil responsiveness to stimuli that trigger degranulation responses. Although many of the receptors we have examined are expressed at reduced levels on apoptotic neutrophils, we found that there was differential loss of certain receptors (e.g. CD16, CD15 and CD120b) and increased expression of aminopeptidase-N (CD13). Together with our previous data showing that expression of certain molecules e.g. LFA-3 (CD58) is not altered during neutrophil apoptosis, these data are suggestive of specific changes in receptor mobilisation and shedding associated with apoptosis. Although reduced expression of CD63 (azurophilic granules) and CR1 (specific granules) indicates that granule mobilisation does not accompany apoptosis, a monoclonal antibody (BOB78), that recognises a $90 \mathrm{kDa}$ antigen localised in intracellular granules, defines a subpopulation of apoptotic neutrophils that exhibit nuclear degradation yet retain intact plasma membranes. BOB78 positive neutrophils were found to bind biotinylated thrombospondin, suggesting that this $\mathrm{mAb}$ defines surface molecular changes associated with
\end{abstract}

exposure of thrombospondin binding moieties. Cell Death and Differentiation (2000) 7, 493-503.

Keywords: neutrophil; apoptosis; carbohydrate; surface molecules

Abbreviations: PS, phosphatidylserine; mAb, monoclonal antibody; DMEM, Dulbecco's modified Eagle's medium

\section{Introduction}

It is now widely accepted that the fate of neutrophil granulocytes, which are recruited in large numbers to a site of inflammation, is programmed cell death, or apoptosis. ${ }^{1-3}$ The neutrophil is a vital component of the body's defence against infectious agents, but uncontrolled release of its formidable array of toxic substances may inflict 'friendly fire' damage on surrounding tissue and propagate the inflammatory response, leading to scarring and tissue destruction. ${ }^{4}$ Indeed, neutrophils and neutrophil products have been implicated in the pathogenesis of a variety of inflammatory diseases including the adult respiratory distress syndrome, idiopathic pulmonary fibrosis, ulcerative colitis, and rheumatoid arthritis. Apoptosis of neutrophils is associated with downregulation of many cellular functions such as adhesion, chemotaxis, phagocytosis, enzyme secretion, generation of a respiratory burst, and responsiveness to external stimuli such as fMLP in vitro. ${ }^{5,6}$ Furthermore, apoptosis is associated with cell surface changes that provide signals for the recognition and phagocytosis of dying granulocytes by macrophages, ${ }^{7}$ a process that results in inhibition of macrophage cytokine production in vitro. ${ }^{8}$ By down-regulating potentially harmful neutrophil functions and triggering their 'anti-inflammatory' clearance by phagocytes, apoptosis provides a mechanism for the safe disposal of inflammatory cells.

It is likely that significant changes in the protein, lipid, and carbohydrate composition of the apoptotic neutrophil plasma membrane play an important role in the 'functional isolation' and subsequent phagocytic clearance of these potentially destructive cells. For example, we have previously shown that neutrophil apoptosis is associated with reduced expression and function of adhesion molecules, providing a mechanism for diminished responses to activation signals that are normally generated by interaction with the extracellular matrix and neighbouring cells. $^{6}$ The molecular alterations on the surface of the apoptotic neutrophil that are responsible for phagocyte recognition have yet to be characterised. Much attention has been focussed on the anionic phospholipid phosphatidylserine (PS), ${ }^{9}$ which is relocated from the inner to the 
outer surface of the plasma membrane during apoptosis. ${ }^{10}$ PS exposure has been implicated in the recognition of apoptotic leukocytes by mouse inflammatory macrophages in vitro, ${ }^{11}$ but PS may not be involved in apoptotic cell recognition by other phagocytes, including human macrophages. $^{12,13}$ Recent evidence implicates ICAM-3 (CD50) present on the apoptotic cell surface as a target recognition structure for macrophage recognition, ${ }^{14}$ although the precise molecular changes associated with 'apoptotic' ICAM-3 remains to be defined. Considering the diversity of phagocyte surface molecules that have been proposed to be involved in the recognition of apoptotic cells (including lectins, the integrin $\alpha v \beta 3$ (CD51/61), $\beta 1$ integrins, CD36, a PS receptor, Class $A$ scavenger receptors, $A B C$ transporters, Complement receptors, and CD14. ${ }^{15-19}$ it is extremely likely that additional undefined molecular changes on the apoptotic cell surface signal phagocyte recognition under different circumstances. We have previously demonstrated that apoptotic and non-apoptotic neutrophils can be defined on the basis of differential expression of Fc $\gamma \mathrm{RIII}$ (CD16). ${ }^{20}$ We have exploited this observation to characterise changes in the surface expression of proteins and carbohydrates associated with neutrophil apoptosis using dual colour flow cytometric analysis with a panel of monoclonal antibodies and lectins. Together these studies further define the molecular alterations that may play important roles in the down-regulation of function and phagocyte recognition of apoptotic neutrophils.

\section{Results and discussion}

\section{Specific alterations in neutrophil surface molecule expression associated with apoptosis}

Neutrophils express on their surface a number of adhesion receptors that interact with extracellular ligands and so act as sensors of the external milieu. During the initiation and resolution of inflammation engagement of adhesion molecules leads to activation of intracellular signal transduction cascades providing mechanisms for the strict regulation of neutrophil function. Reduced neutrophil responsiveness associated with apoptosis is accompanied by altered surface expression and function of adhesion molecules and receptors involved in triggering effector function. ${ }^{5,6}$ Loss of receptor expression may be an effective mechanism for uncoupling cellular responses to extracellular pro-inflammatory stimuli, for example reduced expression of receptors that mediate phagocytosis of opsonized particles e.g. CD16 (FcyRIII), CD32 (Fc $\gamma$ RII), and CD35 (CR1) (see Table 1). In this paper we have extended our analysis of surface alterations associated with neutrophil apoptosis using dual colour flow cytometric analysis.

We examined neutrophil expression of receptors for TNF (CD120a (TNFRp55) and CD120b (TNFRp75). Although freshly isolated neutrophils express low levels of both receptors, expression decreases rapidly $(<3 \mathrm{~h})$ when neutrophils are cultured in vitro (reference ${ }^{21}$ and data not shown). When neutrophils cultured in vitro for $18 \mathrm{~h}$ were examined, we found that although expression of the TNFRp55 was not detectable, TNFRp75 was expressed by the non-apoptotic neutrophils present in these cultures (Table 1). These results raise the possibility that these two receptors show differential regulation during in vitro culture, with initial receptor shedding followed by receptor reexpression in the case of the TNFRp75. However, the TNFRp75 appears to be completely lost following apoptosis. Expression of CD88, the receptor for the potent neutrophil chemoattractant $\mathrm{C} 5 \mathrm{a}$, is downregulated by over $50 \%$ (Table 1). Neutrophil apoptosis has previously been shown to be associated with significantly reduced expression of the fMLP receptor, ${ }^{5}$ which may account for reduced responsiveness to this stimulating bacterial peptide in vitro. It seems likely that down-regulation of receptors for soluble factors that trigger intracellular signal transduction pathways is likely to be an important factor in functional isolation associated with neutrophil apoptosis.

In keeping with previous data that neutrophil apoptosis is associated with down-regulation of adhesion receptors, ${ }^{6}$ significantly reduced expression of ICAM-3 (CD50) was demonstrated (Table 1). ICAM-3 plays a role in leukocyteleukocyte adhesion and has been suggested to act as a ligand for CD14-mediated recognition of apoptotic cells. ${ }^{14}$

Table 1 Altered expression of neutrophil surface molecules associated with apoptosis

\begin{tabular}{|c|c|c|}
\hline Surface molecule & Antigen & Relative expression \\
\hline Phagocytic receptors & $\begin{array}{l}\text { Fc } \gamma \text { RII (CD32) } \\
\text { CR1 (CD35) }\end{array}$ & $\begin{array}{l}0.59 \pm 0.04 \\
0.53 \pm 0.02\end{array}$ \\
\hline Receptors for soluble factors & $\begin{array}{l}\text { C5a receptor (CD88) } \\
\text { TNFRp75 (CD120b) }\end{array}$ & $\begin{array}{l}0.45 \pm 0.05 \\
0.17 \pm 0.02\end{array}$ \\
\hline Immunoglobulin superfamily members & $\begin{array}{l}\text { PECAM-1 (CD31) } \\
\text { ICAM-3 (CD50) } \\
\text { CD66acde } \\
\text { CD66b }\end{array}$ & $\begin{array}{l}0.82 \pm 0.21 \\
0.46 \pm 0.08 \\
0.81 \pm 0.08 \\
0.86 \pm 0.05\end{array}$ \\
\hline Enzymes & aminopeptidase $\mathrm{N}$ (CD13) & $1.24 \pm 0.18$ \\
\hline Integrin-associated proteins & $\begin{array}{l}\text { LIMP (CD63) } \\
\text { uPAR (CD87) }\end{array}$ & $\begin{array}{l}0.71 \pm 0.11 \\
0.53 \pm 0.07\end{array}$ \\
\hline Carbohydrates & $\begin{array}{l}\text { Lewis* (CD15) }^{*} \text { lactosylceramide (CD17) } \\
\text { polysiayl-n-acetyllactoceramide (CD65) } \\
\text { MRP14 (s36.48 mAb) }\end{array}$ & $\begin{array}{l}0.22 \pm 0.05 \\
0.51 \pm 0.14 \\
0.57 \pm 0.05 \\
2.46 \pm 0.53\end{array}$ \\
\hline
\end{tabular}

Dual colour flow cytometric analysis was used to assess relative expression (expressed as mean \pm s.e.m. of at least three independent experiments) of receptors on apoptotic $\left(C D 16^{\text {low }}\right)$ compared with non-apoptotic $\left(C D 16^{\text {high }}\right)$ neutrophils 
In contrast with ICAM-3, expression of PECAM-1 (CD31) and the adhesion regulatory molecule CD66, which are also members of the immunoglobulin superfamily of receptors, was only marginally reduced on apoptotic neutrophils (Table 1). The integrin-associated proteins urokinase-plasminogen activator receptor (uPAR; CD87) and CD63 were down-regulated by 47 and $29 \%$ respectively on apoptotic neutrophils. Both uPAR and CD63 have been implicated as regulators of integrin-mediated adhesion processes, and their reduced expression may play a role in the altered adhesiveness and diminished response to adhesion-mediated stimuli that is associated with neutrophil apoptosis. Interestingly, surface expression of the enzyme aminopeptidase $N$ (CD13), which may play a role in the degradation of soluble peptide mediators, increased during neutrophil apoptosis (Table 1). If aminopeptidase activity is maintained, apoptotic neutrophils could feasibly play a role in the inactivation of proinflammatory cytokines, which may promote resolution of inflammation.

\section{Mechanisms of receptor down-regulation}

Although many neutrophil receptors showed reduced surface expression associated with apoptosis, our data do not support any common mechanism for receptor modulation. Membrane loss may be associated with budding and apoptotic body formation resulting in a net decrease in surface receptor expression. It is worth noting that the extent of cell shrinkage and membrane loss during neutrophil apoptosis is considerably less than in other cell types (such as lymphocytes), and there is little evidence of apoptotic body formation. Although some receptors were expressed at $\sim 80 \%$ of the levels found on non-apoptotic cells, non-specific loss of neutrophil membrane does not account for the observation that some receptors are markedly down-regulated on apoptotic cells (e.g. CD16, CD62L and CD120b). Furthermore, apoptotic and nonapoptotic neutrophils show similar levels of expression of CD58, ${ }^{6}$, CD31 and CD66 (this study) together with the finding that apoptotic neutrophils have increased expression of aminopeptidase- $\mathrm{N}$ (CD13) raises the possibility that receptor down-regulation occurs in a specific manner. In viable cells, levels of surface molecule expression reflect the balance between mobilisation from intracellular stores, recycling via endocytosis, and proteolytic loss from the cell membrane. Since there is increasing evidence that membrane traffic, both to, and from, the plasma membrane may be inhibited during apoptosis, ${ }^{5,22}$ continued proteolytic shedding would result in reduced surface expression of membrane receptors. Thus, differential rates of receptor recycling in viable cells together with differential proteolytic susceptibility would be expected to give rise to a distinct apoptotic cell phenotype. Whilst the principal mechanism for down-regulation of certain receptors (e.g. CD16, CD43, and $\mathrm{CD62L}$ ) may involve proteolytic shedding, this mechanism is unlikely to account for reduced expression of the seven transmembrane G-protein coupled receptors (e.g., fMLP and $\mathrm{C} 5 \mathrm{a}$ receptors). These data suggest that distinct regulatory mechanisms may be involved in changes in expression of surface receptors during activation and apoptosis.

\section{Neutrophil surface carbohydrates}

Expression of neutrophil surface carbohydrates might be expected to parallel the general decrease in glycosylated surface receptors described above. It has been proposed that desialated sugars expressed on apoptotic neonatal rat liver cells play a role in their recognition by phagocyte asialoglycoprotein receptors. ${ }^{23}$ In contrast, examination of the surface of apoptotic mouse thymocytes failed to show any change in carbohydrate expression. ${ }^{24}$ Interestingly, brief treatment of apoptotic neutrophils with $V$. cholerae neuraminidase significantly augmented their phagocytosis by human monocyte-derived macrophages in vitro (Figure 1), whereas treatment of the apoptotic cells with heparinase III or proteinase $\mathrm{K}$ had little effect on recognition. These findings are consistent with the proposal that altered exposure of carbohydrate moieties on apoptotic neutrophils may provide a signal for phagocytic clearance by macrophages. To examine the patterns of surface carbohydrate expression on cultured human neutrophils we used dual colour flow cytometric analysis with antibodies to the major surface glycans CD15 (lactosyl fucosyl pentaose), CDw17 (lactosyl ceramide), and CDw65 (polysialy-n-acetyllactoceramide). Neutrophil apoptosis was associated with a $78 \%$ reduction in expression of the surface carbohydrate Lewis ${ }^{\times}$(CD15) (Table 1) paralleling

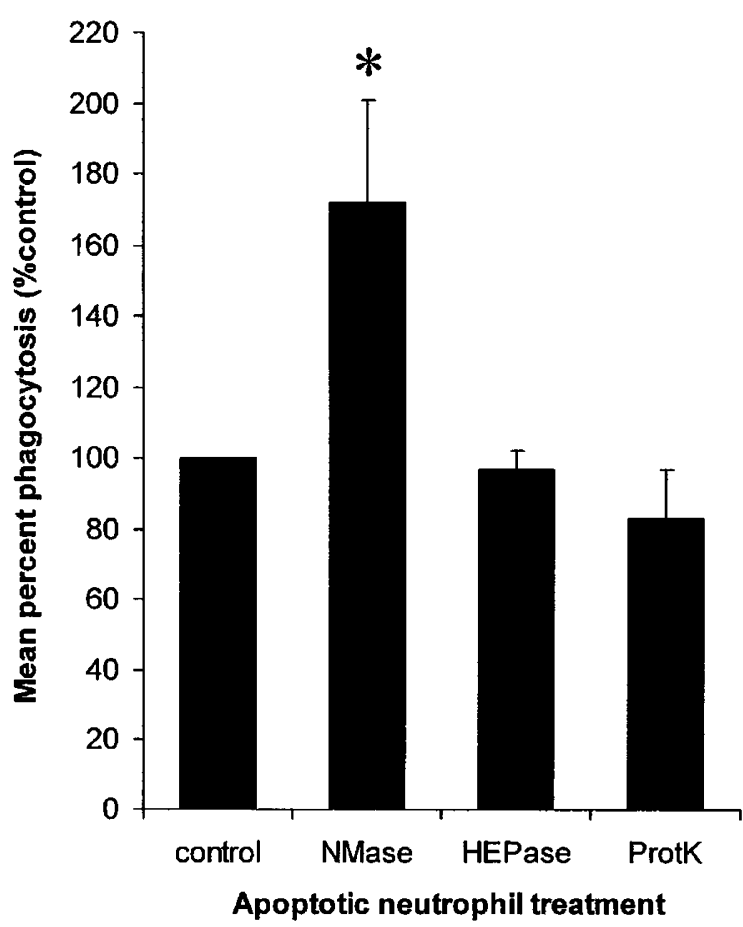

Figure 1 Desialation of apoptotic neutrophils enhances their recognition by macrophages. Aged human neutrophils were washed with PBS prior to $30 \mathrm{~min}$ incubation at $37^{\circ} \mathrm{C}$ with $0.1 \mathrm{U} / \mathrm{ml} \mathrm{V}$. cholerae neuraminidase, $0.5 \mathrm{U} / \mathrm{ml}$ heparinase III, or $100 \mu \mathrm{g} / \mathrm{ml}$ proteinase $\mathrm{K}(10 \mathrm{~min})$. The cells were washed again, resuspended at $4 \times 10^{6} / \mathrm{ml}$ in Iscove's DMEM, and co-incubated with human macrophages for $30 \mathrm{~min}$. Non-ingested cells were washed away, the macrophage monolayer was fixed with glutaraldehyde, and ingested neutrophils were stained with $0.1 \mu \mathrm{g} / \mathrm{ml} \mathrm{DMB} / 0.03 \% \mathrm{H}_{2} \mathrm{O}_{2}$. The percentage of macrophages that had ingested one or more apoptotic neutrophils was assessed by light microscopy. Data are mean \pm S.E.M. of $3-5$ independent experiments. ${ }^{*} P<0.05$ 
expression of sialyl-Lewis ${ }^{\mathrm{x}}$ (SCD15) on apoptotic neutrophils. ${ }^{6}$ The interaction between neutrophil sialyl-Lewis ${ }^{x}$ and $E$ selectin on activated endothelium is vital for the initial tethering and subsequent rolling adhesion that results in recruitment of leukocytes to a site of tissue damage and engagement of CD15 has been shown to modulate neutrophil activation. $^{25}$ High levels of the CD15 carbohydrate are associated with CD18 and CD66 expression of which is largely maintained during neutrophil apoptosis $\left(\mathrm{ref}^{6}\right.$ and Table 1), raising the possibility that specific deglycosylation events may accompany apoptosis. Endogenous neuraminidase activity may give rise to desialation of neutrophil surface carbohydrates following agonist induced activation. ${ }^{26} \mathrm{How}$ ever, the carbohydrate moieties examined here are differentially regulated following $\mathrm{fMLP}$ stimulation: expression of CD15 is augmented, CDw65 shows little change, and there is marked downregulation of CDw17. ${ }^{27}$ In contrast, expression of the surface carbohydrates CDw17 and CDw65 was reduced by $40-50 \%$ during neutrophil apoptosis. One possible explanation is that in the absence of receptor mobilisation from intracellular stores during apoptosis, surface glycosidase activity leads to a net loss of glycan-bearing molecules at the neutrophil surface.

In view of the limited availability of antibodies that bind defined carbohydrate structures, we utilised a panel of labelled lectins to extend our analysis of carbohydrates on the surface of the apoptotic neutrophil. Dual colour flow cytometric analysis was performed with CD16 mAb in conjunction with eight different lectins, each with relative specificity for particular carbohydrate structures. Binding of each lectin to the surface of apoptotic neutrophils was moderately reduced compared with non apoptotic cells (Figure 2a). In contrast, neuraminidase-treated neutrophils exhibited a $95 \%$ reduction in MAL2 binding and a $1100 \%$ increase in PNA binding compared with untreated cells, confirming loss of sialic acid and exposure of galactose residues (Figure 2b). Recent data suggests that exposure of fucose residues is a feature of thymocyte apoptosis. ${ }^{28}$ However, we found that binding of lotus lectin TGP was reduced on apoptosis neutrophils, suggesting that fucose exposure is not a general feature of apoptotic cell membranes.

Together, these data suggest that changes in the degree of desialation of surface carbohydrates associated with neutrophil apoptosis is relatively subtle. Loss of carbohydrate is unlikely to represent the only determinant of recognition and phagocytosis of apoptotic neutrophils, although it remains possible that the degree of glycosylation of specific molecules influences the phagocytic response. Certain heavily glycosylated neutrophil receptors such as CD43, CD44, and CD50 are down-regulated during neutrophil apoptosis. It is tempting to speculate that loss of these receptors may partly account for the reduction in binding of sialic acid-specific lectins observed in this study.

In addition, recent data suggests that CD43 is a negative regulator of lymphocyte adhesion processes, ${ }^{29}$ raising the possibility that loss of CD43 or other heavily sialated receptors may facilitate adhesive interactions between a

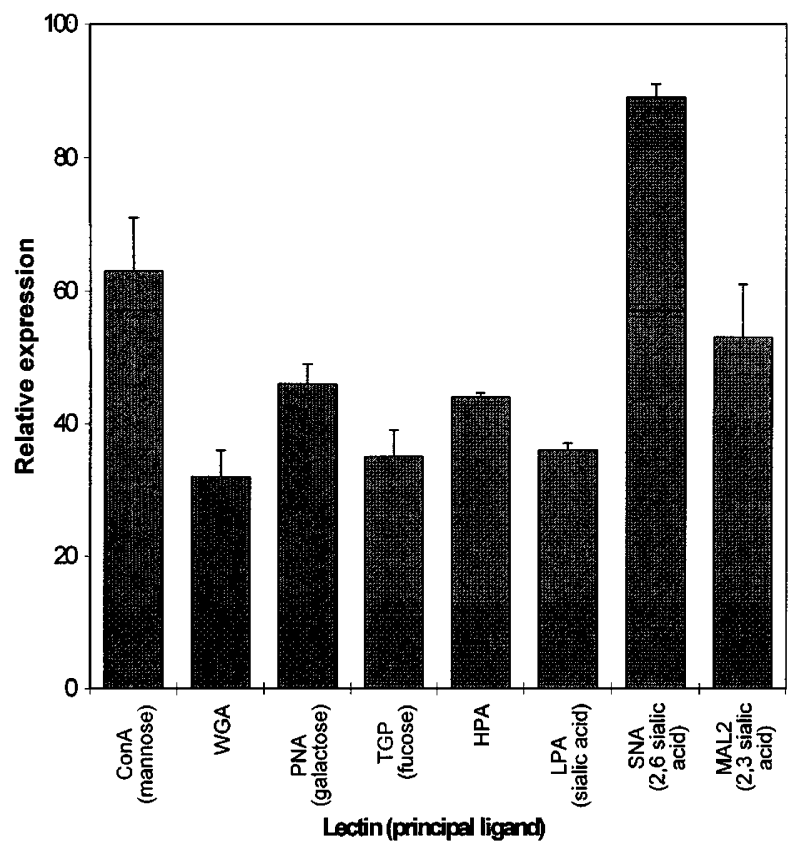

b

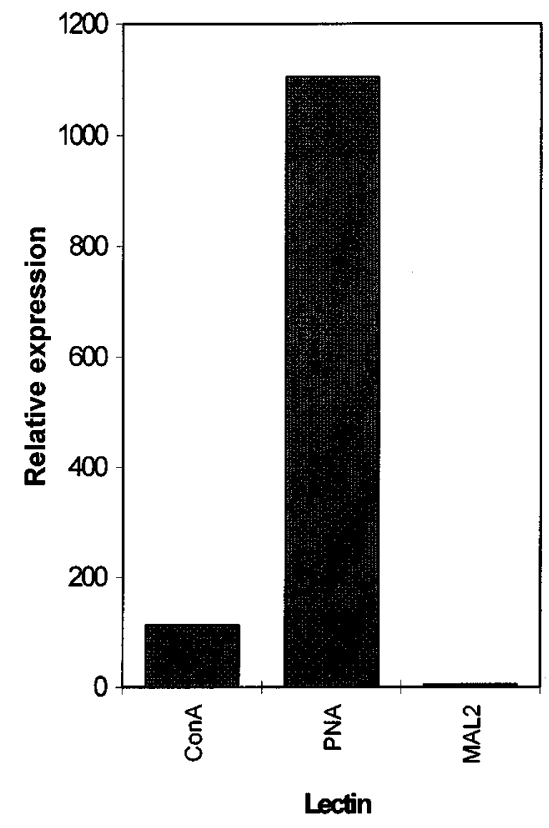

Figure 2 Neutrophil apoptosis is associated with generalised loss of surface sugars. (a) Aged human peripheral blood neutrophils (approximately 50\% apoptotic) were incubated on ice with CD16 mAb 3G8, washed, and then incubated with F(ab') ${ }_{2}$ goat anti-mouse PE together with the FITC-labelled lectin (except for MAL2 where a biotinylated lectin was used followed by streptavidin-FITC). The cells were washed and dual colour flow cytometric analysis was performed following appropriate color compensation. The binding of lectins to apoptotic (CD16 $\left.{ }^{\text {low }}\right)$ neutrophils is expressed as a percentage of the binding to non-apoptotic (CD16 ${ }^{\text {high }}$ ) neutrophils. Values are mean \pm S.E.M. of three independent experiments. $P<0.05$ for all lectins. (b) Freshly isolated peripheral blood neutrophils were treated with $0.1 \mathrm{U} / \mathrm{ml} \mathrm{V}$. cholerae neuraminidase prior to assessment of lectin binding. Results from one representative experiment of three that were performed are shown 
apoptotic neutrophils and macrophages that lead to phagocytosis.

\section{BOB78: a monoclonal antibody marker for 'late apoptotic' neutrophils}

By screening a panel of hybridoma supernatants using indirect immunofluorescence and flow cytometric analysis we identified a monoclonal antibody, termed BOB78, that binds to a subpopulation of in vitro-cultured neutrophils. Dual labelling studies using a CD16 monoclonal antibody (mAb) to define apoptotic cells revealed that BOB78-reactive cells represented a subpopulation of apoptotic cells (Figure $3 b$ ). The percentage of neutrophils that showed morphological features of apoptosis in cytocentrifuge preparations after $24 \mathrm{~h}$ in culture $(74.9 \pm 7.1 \%(n=14))$ consistently exceeded the percentage of BOB78 expressing neutrophils (19.3 $\pm 5.6 \%$ $(n=7))$. We therefore compared the temporal relationship between surface expression of the BOB78 antigen and the acquisition of a CD16 ${ }^{\text {low }}$ phenotype during in vitro culture of a

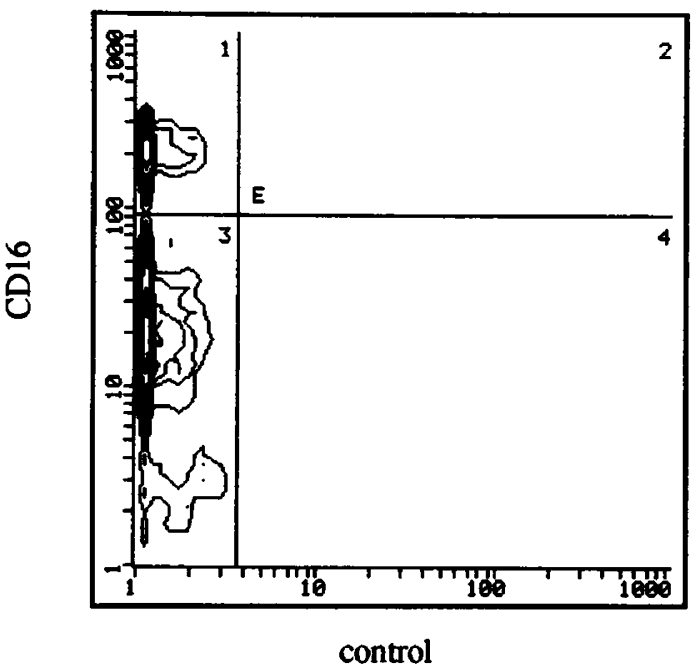

b

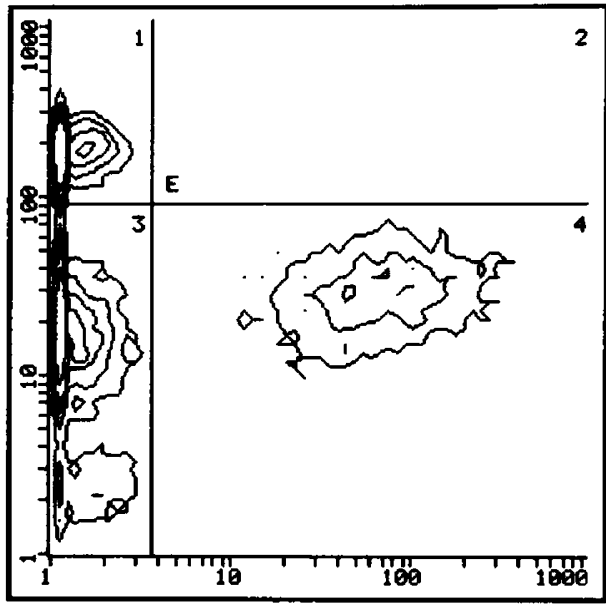

BOB 78

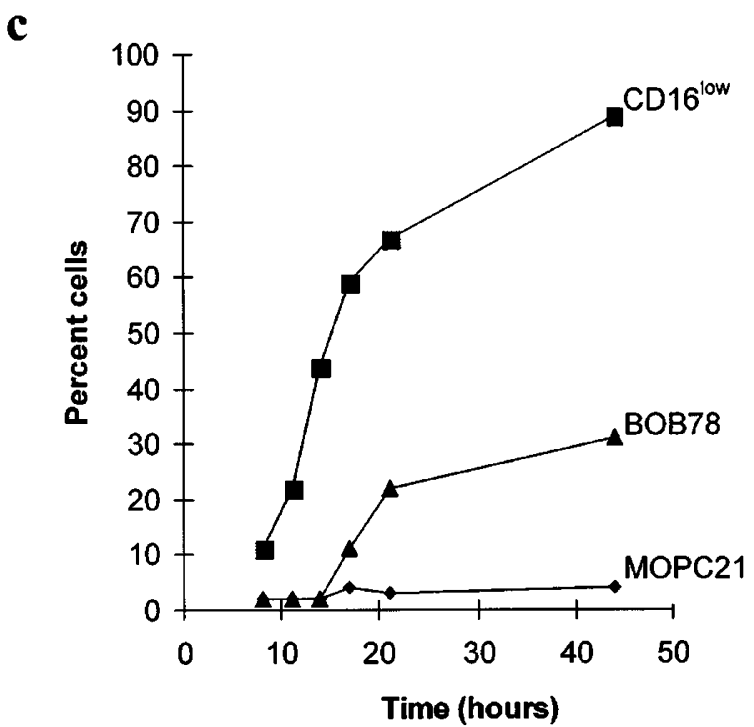

Figure 3 Analysis of binding of $\mathrm{mAb} B O B 78$ to neutrophils cultured in vitro. Neutrophils cultured for $24 \mathrm{~h}$ in vitro were immunolabelled with either mAb MOPC21C (a) or BOB78 (b), and bound antibody was detected with PE-conjugated F(ab') 2 anti-mouse Ig. Cells were co-labelled with FITC-conjugated CD16 mAb $3 G 8$. Histograms representative of results from at least four independent experiments are shown. The percentage of cells present in regions $1-4$ was as follows: (a) $33 \%, 1 \%, 65 \%, 0.9 \%$; (b) $33 \%, 1 \%, 49 \%, 17 \%$. (Note the presence of $5 \%$ CD $16^{\text {low }}$ eosinophils in this experiment). In all experiments, BOB78 reactivity was restricted exclusively to the CD16 ${ }^{\text {low }}$ or apoptotic subpopulation of neutrophils. (c) Freshly isolated neutrophils were cultured in polypropylene 96 well plates for various times. Cytocentrifuge preparations were stained with Diff-Quik and examined for morphological features of apoptosis (a minimum of 500 cells was counted for each time point). Indirect immunofluorescence analysis was used to determine the binding of either control mAb or BOB78. Results from one representative experiment of three performed are expressed as percentage of cells with apoptotic morphology, or for mAb binding, the percentage of cells positive when compared with FITC anti-mouse Ig alone 
neutrophils. Morphological apoptosis and CD16 ${ }^{\text {low }}$ phenotype can be observed as early as $10 \mathrm{~h}$ in culture, with a rapid increase between 14-20 h. However, BOB78 expression was not seen until later in the culture period, typically $18-$ $24 \mathrm{~h}$ (Figure $3 \mathrm{c}$ ) indicating that expression of the BOB78 antigen was delayed temporally when compared with classical markers of neutrophil apoptosis. At longer time points ( $>36 \mathrm{~h}$ ), estimation of BOB78 reactivity became more difficult since necrotic cells were also present by propidium iodide staining. However, approximately $25 \%$ of those cells that were PI 'negative' displayed BOB78 antigen expression (Figure $3 \mathrm{c}$ ). Together, these results suggest that $a$ subpopulation of apoptotic neutrophils express the BOB78 antigen, possibly late during the apoptotic process.

\section{Phenotypic characteristics of the neutrophil subpopulation defined by mAb BOB78}

We next isolated BOB78-reactive neutrophils using immunomagnetic beads (Mini-MACS). Isolated cells had intact plasma membranes as determined by trypan blue exclusion (mean viability 93\%; $n=3$ ). Figure $4 a$ shows typical laser scatter properties of the isolated cells (dot plot) when compared with the unseparated population (contour plot). The restricted laser scatter properties of the BOB78 reactive neutrophils suggested that these neutrophils were relatively homogeneous in terms of size and granularity compared with unseparated neutrophils, and raised the possibility that expression of the BOB78 antigen occurs concomitantly with an alteration in cell volume or granule content during apoptosis. Morphological examination of BOB78-reactive neutrophils using the DNA binding dye acridine orange revealed that cells with condensed nuclear material (Figure $4 \mathrm{~b})$ represented less than $5 \%$ of the cells. In contrast, the majority of cells showed evidence of extensive nuclear degradation (Figure $4 \mathrm{c}-\mathrm{e}$ ) suggesting that $\mathrm{BOB} 78$ reactive neutrophils represent those cells which have undergone changes associated with 'late' apoptosis, but which have not sustained loss of membrane integrity or loss of granule contents.

\section{'Late' apoptotic neutrophils bind thrombospondin}

Interestingly, dual immunofluorescence analysis using BOB78 and biotinylated thrombospondin revealed that both BOB78 and thrombosponding bind to the same subpopulation of apoptotic neutrophils (Figure 5). Thrombospondin has been proposed to form a 'molecular bridge' between the surface of the apoptotic neutrophil and the phagocyte that permits recognition and subsequent ingestion of the apoptotic cell, ${ }^{30}$ but the thrombospondin-binding moiety on the apoptotic cell surface remains to be defined. Our observations provide evidence that there is a thrombospondin-binding subpopulation of apoptotic neutrophil that is defined by BOB78.

Our preliminary data indicates that binding of BOB78 does not inhibit macrophage recognition of apoptotic neutrophils. Indeed, when in vitro cultured neutrophils labelled using BOB78 are used as targets for macrophage phagocytosis, labelled cells can be detected within macrophages (data not shown). Our data indicate that a)

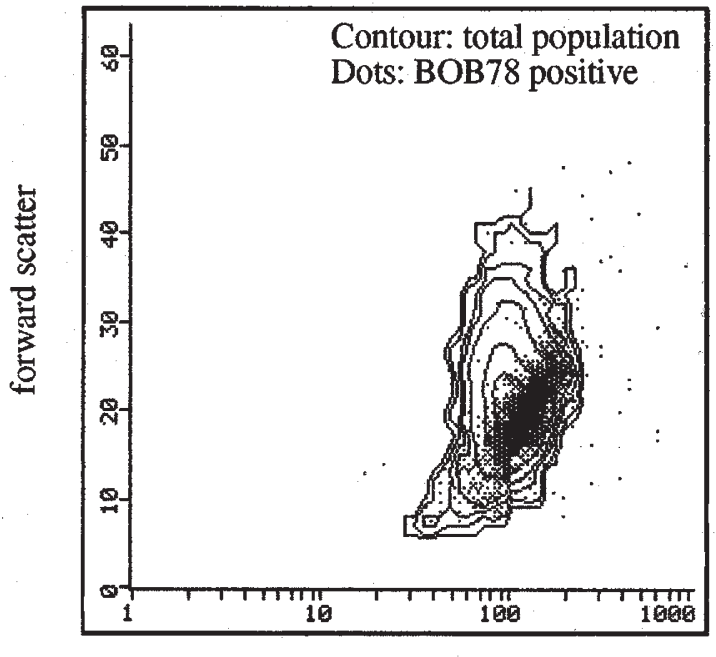

side scatter b)

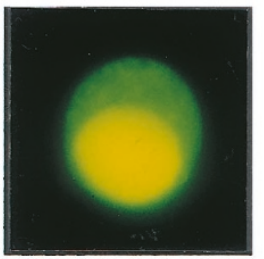

d)

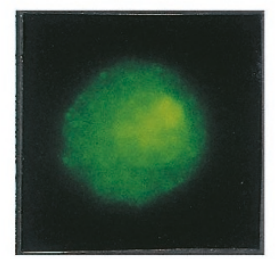

c)

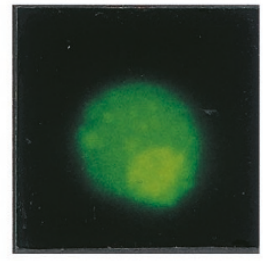

e)

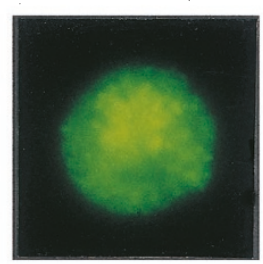

Acridine orange nuclear morphology

Figure 4 Physical properties and nuclear morphology of BOB78 reactive neutrophils. Peripheral blood neutrophils were cultured for $24 \mathrm{~h}$ in vitro and BOB78 reactive neutrophils were separated immunomagnetically using the MiniMacs system. (a) Shows the restricted laser scatter properties of the BOB78 population (dot plot) when compared with the total neutrophil population (contour plot). Immunomagnetically separated BOB78 reactive neutrophils were also analyzed microscopically following staining with acridine orange $(\mathbf{b}-\mathbf{e})$. Typical morphologies observed for BOB78 reactive neutrophils are shown. Quantitation (at least 500 cells were counted) revealed that neutrophils with distinct pyknotic nuclei (b) represented $<5 \%$ of the total population, whereas $>95 \%$ of cells showed evidence of degradation of nuclear material (c, d, e) 

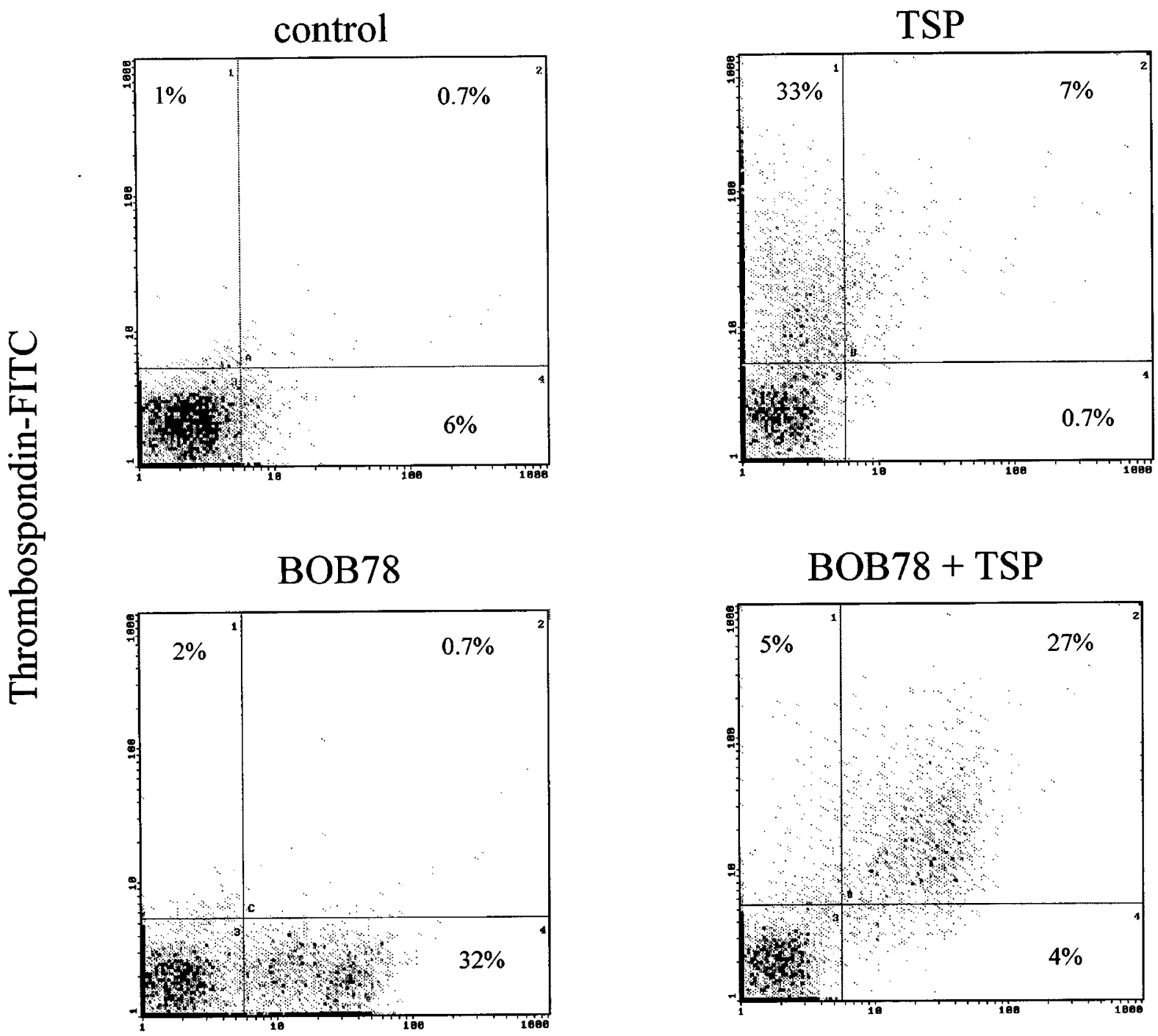

\section{BOB78 + TSP}

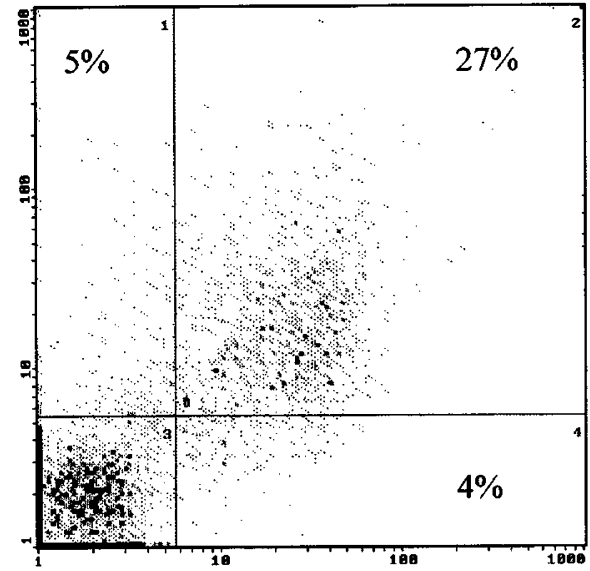

\section{Phycoerythrin anti-mouse IgM}

Figure 5 Binding of BOB78 and thrombospondin to neutrophils cultured in vitro. Neutrophils cultured for $24 \mathrm{~h}$ in vitro were immunolabelled with control mouse IgM $\mathrm{mAb}$ or BOB78, and bound antibody was detected with PE-conjugated $\left.\mathrm{F}(\mathrm{ab})_{2}\right)_{2}$ goat anti-mouse Ig. Cells were co-labelled with biotinylated thrombospondin and FITC-streptavidin. Biotinylated goat anti-rabbit IgG together with FITC streptavidin was used as a control for TSP binding. TSP binding was displaced by excess unlabelled thrombospondin or the addition of human serum indicating specificity (data not shown). Histograms representative of results from at least three independent experiments are shown

BOB78 may be a useful tool for analysis of the molecular pathways involved in the clearance of apoptotic and 'late' apoptotic cells and we are currently further investigating the molecular mechanism(s) by which BOB78 positive neutrophils are phagocytosed.

\section{BOB78 defines a $90 \mathrm{kDa}$ molecule present in a granular compartment}

In view of these intriguing observations, we sought to further characterize the binding of the BOB78 mAb. BOB78 did not bind freshly isolated erythrocytes, platelets, lymphocytes, monocytes, or neutrophils (data not shown). However, all leukocytes were found to express the BOB78 antigen when permeabilized prior to flow cytometric analysis (data not shown), raising the possibility that specific expression of an intracellular antigen at the cell surface occurred during in vitro culture. Since the proportion of cells staining with BOB78 always exceeded the proportion of cells with disrupted plasma membranes, as assessed by exclusion of trypan blue or propidium iodide (data not shown), it seems unlikely membrane permeability changes allowed access of antibodies to intracellular antigens. Analysis of the binding characteristics of a number of antibodies that define 
$\mathbf{A}$
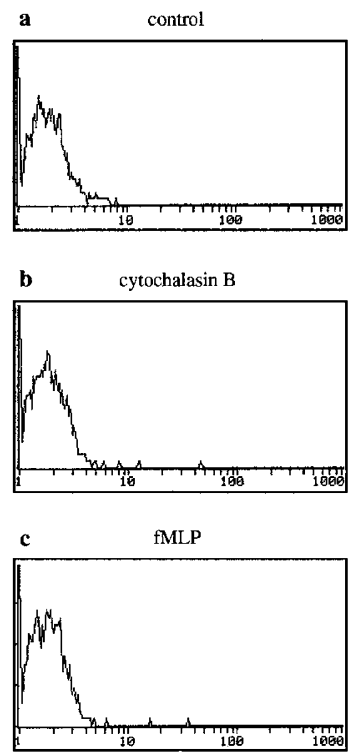

d $\quad$ MLP + cytochalasin B

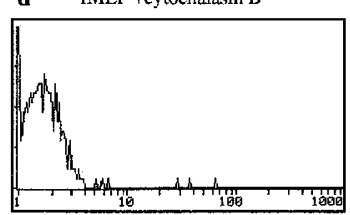

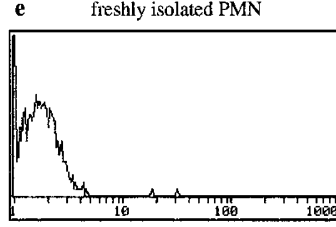

f $\quad 24 \mathrm{~h} \mathrm{PMN}$

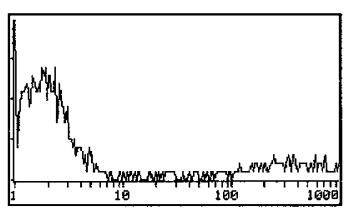

g neuraminidase

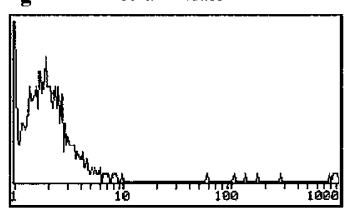

h

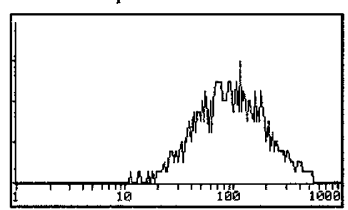

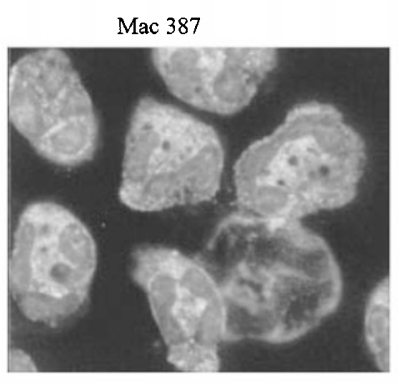

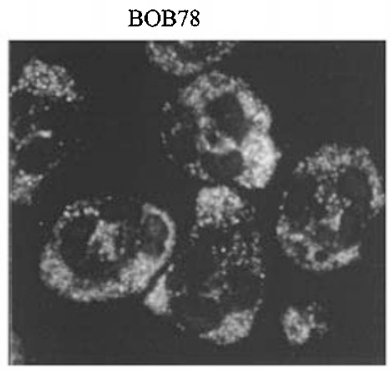

C

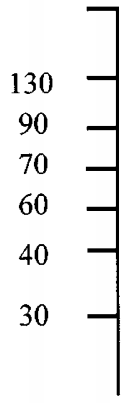

M. Wt.

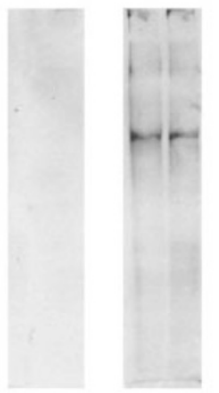

control BOB78
D

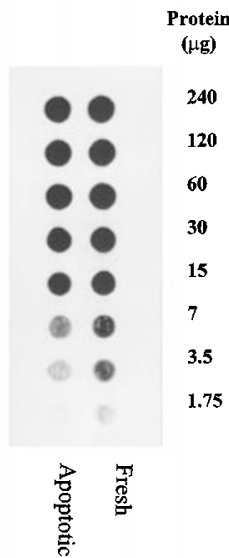

Figure 6 Characterization of mAb BOB78 binding to neutrophils. (A) Flow cytometric determination of binding of mAb BOB78 to (a) untreated freshly isolated human peripheral blood neutrophils, and to neutrophils following treatment with (b) $5 \mu \mathrm{g} / \mathrm{ml}$ cytochalasin B; (c) $10-7 \mathrm{M}$ fMLP; (d) $5 \mu \mathrm{g} / \mathrm{ml}$ cytochalasin B and $10-7 \mathrm{M}$ fMLP; (g) $0.05 \mathrm{U} / \mathrm{ml}$ neuraminidase; and $(\mathrm{h}) 1 \mu \mathrm{g} / \mathrm{ml}$ lysophosphatidyl choline $/ 1 \%$ formaldehyde to permeabilise the cells. Panel (f) shows BOB78 binding to neutrophils that have been cultured for $24 \mathrm{~h}$ in Iscove's DMEM containing $10 \%$ autologous serum. Representative histograms showing recorded log fluorescence from one representative experiment of four are shown. (B) Micrographs showing indirect immunofluorescence labelling of cytocentrifuge preparations with Mac-387 which defines a cytoplasmic antigen $(\mathrm{p} 8,14)$ or BOB78 as described in Materials and Methods. Binding of isotype matched controls was low and under the conditions used for photography for mAb BOB78 and Mac-387, no staining was observed. (C) Freshly isolated neutrophil lysates were separated by SDS-PAGE under non-reducing conditions and transferred to nitrocellulose membranes. Binding of BOB78 or an isotype matched control to separated proteins was assessed by ECL detection of HRP conjugated anti-mouse immunoglobulin antibody. The representative gel shown here illustrates BOB78 binding to a $90 \mathrm{kDa}$ protein present in neutrophils. (D) Dot blot analysis of the levels of BOB78 antigen present in freshly isolated versus highly apoptotic neutrophil lysates. Known quantities of total lysate were adsorbed to nitrocellulose using a dot-blot apparatus and probed with BOB78 antibody. Bound antibody was visualised by ECL detection of HRP conjugated anti-mouse immunoglobulin antibody. In the representative dot blot shown here, $74 \%$ of the neutrophils in the apoptotic lysate showed morphological features of apoptosis

intracellular molecules including actin $^{31}$ supported the suggestion that exposure of cytoplasmic antigens is not a general phenomenon associated with apoptosis (data not shown). However, one antibody (s36.48) recognising MRP14 (S100A9) was consistently found to bind at low levels to cultured neutrophils, but not to freshly isolated cells. Dual immunofluorescence analysis revealed that unlike BOB78, this $\mathrm{mAb}$ bound at low levels to all CD16 ${ }^{\text {low }}$ apoptotic cells (Table 1). Recent data suggest that a receptor for MRP14 may be present on neutrophils. ${ }^{32}$ One interpretation of these data is that MRP14 is bound specifically to receptors present on the surface of apoptotic neutrophils. MRP14 is present as a heterodimeric complex with MRP8 within the cytoplasm of neutrophils, ${ }^{33}$ although it has previously been suggested that release of the protein may occur under certain conditions. Since antibodies specific for MRP8 do not bind to apoptotic neutrophils (data not shown) it is possible that only certain epitopes are available for binding on membrane bound
MRP8,14. Alternatively, the s36.48 $\mathrm{mAb}$ may bind to molecules related immunologically to MRP8,14 that are present on the surface of apoptotic neutrophils.

We next tested whether BOB78 antigen could be induced by $\mathrm{fMLP}$, either alone or in combination with cytochalasin B, which induces secretion of azurophilic granules in addition to specific and C-type granules. ${ }^{34}$ In addition, neutrophil receptors for thrombospondin have been suggested to be present in granules that can be mobilised by $\mathrm{fMLP} /$ cytochalasin treatment. ${ }^{35}$ However, no reactivity of BOB78 was observed following these treatments (Figure 6a) despite marked increases in expression of receptors present in these compartments (CD11b and CD35), suggesting that acquisition of the BOB78 antigen during in vitro culture does not occur simply as a result of neutrophil granule mobilisation. Furthermore, we did not observe increased expression of CD63 (azurophilic granules (Table 1) or CR1 (CD35, specific granules Table 1) on apoptotic neutrophils. However, indirect 
immunofluorescence analysis indicated that the BOB78 antigen appeared to be localised in a granular compartment (Figure 6b). These observations raise the possibility that there is restricted mobilisation of granule contents occurs during late apoptosis. In repeated experiments, we failed to identify specific proteins recognised by BOB78 using immunoprecipitation techniques when membranes were labelled with either $\mathrm{I}^{125}$ or biotin (data not shown). However, we were able to consistently demonstrate reactivity with a single protein band of apparent molecular weight of $90 \mathrm{kDa}$ in neutrophil lysates (Figure 6c). The molecular weight was not affected by reduction, indicating that this molecule probably exists as a monomer. We next sought to identify whether neutrophil apoptosis was associated with biochemical modification of the BOB78 antigen that conferred membrane exposure of the antigen. However, these studies were complicated by proteolysis in apoptotic neutrophil samples, with a major breakdown product at $35 \mathrm{kDa}$ (data not shown), possibly as a result of protease activation that accompanies cell death in neutrophils. We therefore estimated the relative $\mathrm{BOB} 78$ antigen concentration in freshly isolated and apoptotic neutrophils by dot-blotting. As can be seen in Figure 6d, highly apoptotic (>70\%) neutrophil preparations had similar levels of BOB78 antigen to freshly isolated neutrophils, indicating that large scale loss of the BOB78 antigen did not accompany apoptosis.

\section{Conclusion}

We have performed an extensive analysis of the surface phenotype of apoptotic neutrophils. Specific alterations in receptor profiles of apoptotic neutrophils is likely to contribute to the characteristic 'functional down-regulation' of these cells. Subtle changes in the carbohydrate composition of surface molecules may further influence adhesive interactions with phagocytes. In addition, we have characterised a monoclonal antibody, BOB78, that binds specifically to a subpopulation of apoptotic neutrophils, possibly representing cells that are 'late' apoptotic. The changes that result in expression of the BOB78 antigen during apoptosis are not known, but it is possible that 'inappropriate' expression of molecules in the plasma membrane occurs as a result of loss of maintenance of compartmentalisation. Alternatively, membrane 'blebbing' and fusion events associated with cell volume/density changes could result in surface expression of membrane antigens normally restricted to intracellular compartments and serve to mark these cells for recognition by phagocytes.

\section{Materials and methods}

\section{Antibodies and other reagents}

All biochemicals were purchased from Sigma Chemical Co., Poole, UK, unless otherwise stated. Cell culture materials were from Life Technologies, Paisley, Scotland, UK and cell culture plastic was from Falcon Plastics, provided by A\&J Beverage, Edinburgh, UK. Percoll was from Pharmacia, St. Albans, UK; FITC- and PE-conjugated $\mathrm{F}\left(\mathrm{ab}^{\prime}\right)_{2}$ goat anti-mouse Ig were from Dako Ltd, High Wycombe, UK.; Streptavidin-FITC was from Amersham; and FITC-donkey anti-rabbit Ig was from the Scottish Antibody Production Unit, Lanarkshire.
Labelled lectins were from Sigma, except for SNA-FITC and MAL2biotin from Vector Laboratories, Peterborough, UK.

Monoclonal antibody BOB78 (IgM isotype) was prepared by fusion of splenocytes from a BALB/c mouse immunised with the human myelomonocytic cell line THP-1 (obtained from the ECACC, Porton Down, UK) with Sp2/0'-Ag14 (ECACC) non-secreting myeloma cell line. Fusion products secreting $\mathrm{Ig}$ were then tested further in flow cytometry for reactivity with apoptotic, but not freshly isolated neutrophils and sub-cloned twice prior to further analysis. No previously characterised antibodies that we have tested showed similar reactivity to $\mathrm{mAb} B O B 78$ suggesting that the antigen recognised by BOB78 may be unique. The hybridoma $3 G 8$ (CD16) was the generous gift of Dr J Unkeless, Mount Sinai Medical School, New York. FITC-conjugated $3 G 8$ was prepared as described previously ${ }^{20}$ and used at a final concentration of $2 \mu \mathrm{g} / \mathrm{ml}$. Control IgM mAb was obtained from Coulter (Luton, UK) and mAb MOPC21C (IgG1) was obtained from the ECACC and grown in DMEM+10\% FCS.

\section{Cell isolation}

Mononuclear cells and neutrophils were isolated from peripheral blood by dextran sedimentation and discontinuous Percoll gradient centrifugation as described. ${ }^{20,36,37}$ Neutrophils were cultured at $4 \times 10^{6} / \mathrm{ml}$ in Iscove's modification of Dulbecco's modified Eagle's medium (DMEM) containing $10 \%$ autologous serum at $37^{\circ} \mathrm{C}$ in a $95 \%$ air $/ 5 \% \mathrm{CO}_{2}$ atmosphere for $20 \mathrm{~h}$, during which time a proportion of the cells underwent apoptosis. ${ }^{1}$ Apoptosis was confirmed by assessing nuclear morphology of Geimsa stained cytocentrifuge preparations under light microscopy. For phagocytosis experiments, mononuclear cells were suspended at $4 \times 10^{6} / \mathrm{ml}$ in Iscove's DMEM and adhered to cell culture plates during incubation at $37^{\circ} \mathrm{C}$ for $1 \mathrm{~h}$. Adherent cells (monocytes) were washed twice in PBS. Monocytes/macrophages were cultured for 5-7 days in Iscove's DMEM containing $10 \%$ autologous serum, and the medium was changed on day three. Macrophage phagocytosis of apoptotic neutrophils was determined as previously described. ${ }^{1,11}$

For staining of cells using acridine orange, cells were incubated with $1 \mu \mathrm{g} / \mathrm{ml}$ of acridine orange in PBS and examined using an Olympus $\mathrm{BH}-2$ fluorescence microscope.

\section{Purification of thrombospondin}

Thrombospondin was purified from thrombin-activated platelets as described. ${ }^{38}$ Briefly, platelets from two cytophoresis packs (generously provided by the Scottish National Blood Transfusion Service) were washed three times in HEPES buffered saline ( $\mathrm{pH} 7.4)$ containing $5 \%$ acid citrate dextrose then resuspended in $\mathrm{HEPES} / \mathrm{NaCl}$ containing $50 \mathrm{mM}$ glucose prior to stimulation with thrombin ( $1 \mathrm{U} / \mathrm{ml}$ final). After $2 \mathrm{~min}$ at $37^{\circ} \mathrm{C}$ with continuous stirring, the activity of thrombin was stopped by addition of hirudin $(4 \mathrm{U} / \mathrm{ml})$. Platelet releasate was centrifuged at $25000 \times g$ for $20 \mathrm{~min}$ and applied to gelatin Sepharose and Heparin Sepharose columns arranged in tandem. The $0.55 \mathrm{M}$ $\mathrm{NaCl}$ eluate from the heparin column was concentrated using an Amicon ultra filtration unit (Amicon Inc., Gloucestershire; UK), prior to gel filtration using Sephacryl S300 (Pharmacia, Milton Keynes, UK). Thrombospondin containing fractions were identified by gel electrophoresis/immunoblotting and pure pooled thrombospondin was concentrated to approximately $2 \mathrm{mg} / \mathrm{ml}$ and stored frozen $\left(-80^{\circ} \mathrm{C}\right)$ until required. Thrombospondin was biotinylated following dialysis into $0.1 \mathrm{M}$ sodium bicarbonate buffer $\mathrm{pH} 8.3$ by addition of NHS-LC biotin (Pierce and Warriner, Chester, UK) to a final concentration of $20 \mu \mathrm{g} /$ $\mathrm{ml}$. After incubation on ice for $5 \mathrm{~h}$ excess biotin was removed by gel 
filtration using S300 Sephacryl (Pharmacia). Conjugation of thrombospondin with biotin was confirmed using gel electrophoresis/ electrophoretic transfer to nitrocellulose and detection of biotinylated proteins with horseradish peroxidase-conjugated streptavidin and Enhanced Chemiluminescence (Amersham, UK).

\section{Immunomagnetic selection of BOB78-reactive cells}

Neutrophils $\left(5 \times 10^{7}\right.$ total) were cultured overnight as described above and then incubated with saturating concentrations of BOB78 on ice for $30 \mathrm{~min}$ and washed prior to incubation with Dynabeads M-450 (Dynal) at a bead:cell ratio of $10: 1$ for $40 \mathrm{~min}$ on a spiramix at $4{ }^{\circ} \mathrm{C}$ Dynabeads and bound cells were then depleted using a magnetic particle concentrator (MPC-1, Dynal). BOB78-depleted cells were then washed in Iscove's DMEM. For positive selection, cultured neutrophils $\left(5 \times 10^{7}\right.$ total) were incubated with saturating concentrations of BOB78 on ice for $30 \mathrm{~min}$, washed once and resuspended in $1.2 \mathrm{ml}$ of degassed PBS with $150 \mu \mathrm{l}$ of rat anti-mouse IgM magnetic microbeads (Eurogenetics, UK) for $20 \mathrm{~min}$ at room temperature. Labelled cells were then applied to a Mini-MACS column (Eurogenetics, UK) preequilibrated with degassed PBS and allowed to pass through the column at a flow rate of $\sim 150 \mu \mathrm{l} / \mathrm{min}$. The column was then washed with $2.5 \mathrm{ml}$ of PBS prior to elution with PBS with the column removed from the magnet to allow the BOB78 labelled neutrophils to be recovered. BOB78-enriched cells were then washed as described above.

\section{Flow cytometry and immunofluorescence analysis}

Antibody labelling of intact cells was performed using indirect immunofluorescence and flow cytometry with an EPICS Profile II (Coulter Electronics, Luton, UK) as previously described., ${ }^{6,20}$ For double labelling experiments, $\mathrm{PE}$-conjugated $\mathrm{F}\left(\mathrm{ab}^{\prime}\right)_{2}$ goat anti-mouse immunoglobulin was used as a second layer and an additional incubation with FITC-labelled 3G8 (CD16 mAb) was performed prior to washing and flow cytometric analysis. Binding of biotin-thrombospondin to cells was assessed by flow cytometry. Biotin-thrombospondin (or biotinylated rabbit immunoglobulin (Amersham) as a control) was incubated with cells in HEPES-buffered saline containing $\mathrm{Ca}^{2+}$ and $\mathrm{Mg}^{2+}$ for $30 \mathrm{~min}$ on ice. Cells were washed and then incubated in streptavidin-FITC for a further 20 min prior to washing and flow cytometric analysis. For some experiments cells were labelled with $\mathrm{BOB} 78$ or IgM control mAb, and bound antibody was detected using goat anti-mouse IgM-PE prior to analysis of thrombospondin binding.

Air-dried cytocentrifuge preparations were fixed in $1 \%$ paraformaldehyde and then permeabilised with $0.1 \%$ nonidet P 40 . Slides were washed thoroughly in PBS and then blocked with $10 \%$ human $A B$ serum in PBS. Slides were then incubated with antibodies for $1 \mathrm{~h}$ in PBS containing $0.2 \%$ BSA and $0.1 \%$ sodium azide. Bound antibody was detected using FITC-conjugated $F\left(a b^{\prime}\right)_{2}$ goat anti mouse Ig (Dako). Slides were mounted in $50 \%$ glycerol and photographed using an Olympus $\mathrm{BH}-2$ microscope fitted with a fluorescent lamp attachment.

\section{Lectin binding}

Aged human peripheral blood neutrophils (approximately $50 \%$ apoptotic) were incubated for $30 \mathrm{~min}$ on ice with CD16 mAb 3G8, washed, and then incubated for 30 min with 1:40 $\mathrm{F}\left(a b^{\prime}\right)_{2}$ goat antimouse PE together with the FITC-labelled lectin (except for MAL2 where the biotinylated lectin was used followed by 1:50 streptavidin-
FITC for $30 \mathrm{~min}$ ). The lectins used were concanavalin A (ConA from Concanavia ensiformis; $5 \mu \mathrm{g} / \mathrm{ml}$; principal ligand mannose); wheat germ agglutinin (WGA from Triticum vulgaris; $5 \mu \mathrm{g} / \mathrm{ml}$; (N-acetylglucosamine)2); peanut agglutinin (PNA from Arachis hypogaea; $50 \mu \mathrm{g} /$ $\mathrm{ml}$; galactose); Lotus lectin (TGP from Tetragonolobus purpureas; $50 \mu \mathrm{g} / \mathrm{ml}$; fucose); Helix pomatia (HPA; $50 \mu \mathrm{g} / \mathrm{ml}$; N-acetylgalactosamine); Limulus polyphemus (LPA; $50 \mu \mathrm{g} / \mathrm{ml}$; sialic acid); elderberry lectin (SNA from Sambrucus nigra; $10 \mu \mathrm{g} / \mathrm{ml} ;(2-6$ sialic acid); and Maackia amurensis (MAL2; $50 \mu \mathrm{g} / \mathrm{ml} ;(2-3$ sialic acid). The cells were washed and dual colour flow cytometric analysis was performed following appropriate colour compensation. An effect of bound $\mathrm{mAb}$ $3 G 8$ on subsequent lectin binding was excluded by examining lectin binding to a mixed population of 3G8-labelled and unlabelled freshly isolated neutrophils.

\section{SDS-PAGE and immunoblotting}

Freshly isolated neutrophils were lysed $\left(2 \times 10^{7}\right.$ cells $\left./ \mathrm{ml}\right)$ in $25 \mathrm{mM}$ Tris $\mathrm{pH} 7.4$ containing $0.14 \mathrm{M} \mathrm{NaCl}, 1 \% \mathrm{NP}-40,0.5 \%$ sodium deoxycholate and a cocktail of protease inhibitors (Boehringer Mannheim). Protein concentration was determined using a detergent compatible protein estimation kit as directed by the manufacturer (Pierce and Warriner, Chester, UK). For dot blotting, known quantities of neutrophil lysates were adsorbed to nitrocellulose using a dot-blot manifold (Schleicher and Schuell, supplied by Inverclyde Biologicals, Strathclyde, UK). For SDS-PAGE analysis, cell lysates were diluted 1:1 with $2 \times$ SDS sample buffer and approximately $30 \mu \mathrm{g}$ of total protein subjected to SDS-PAGE under reducing conditions and proteins transferred to nitrocellulose (Amersham, Buckingham UK) as previously described. ${ }^{39}$ After blockade of non-specific binding by incubation of membranes in PBS containing $0.05 \%$ Tween 20 and $5 \%$ non-fat milk powder for $60 \mathrm{~min}$, membranes were probed using BOB78 or MOPC21C diluted in PBS-Tween-20, washed thoroughly and bound antibody detected using HRP conjugated rabbit anti-mouse immunoglobulin (Dako, Oxford, UK). Membrane bound HRP activity was detected by ECL using a kit from Amersham (Buckingham, UK) and BioMax film (Kodak).

\section{Statistical analysis}

Results are presented as mean (S.E.M.), and n=number of independent experiments using cells from different donors. Differences were analysed by ANOVA and the Tukey multiple comparison test using Graphpad Instat software (San Diego, CA, USA).

\section{Acknowledgements}

We would like to thank Dr Mary McElroy for her advice relating to dot-blot analysis and Dr Laura Meagher for critical comment. This work was supported by the University of Edinburgh (Faculty of Medicine fellowship: SP Hart) and the Medical Research Council (Programme grant G9016491) supported this work.

\section{References}

1. Savill JS, Wyllie AH, Henson JE, Walport MJ, Henson PM and Haslett C (1989) Macrophage phagocytosis of aging neutrophils in inflammation: programmed cell death in the neutrophil leads to its recognition by macrophages. J. Clin. Invest. 83: 865-875

2. Savill JS and Haslett C (1994) Fate of neutrophils. In Immunopharmacology of Neutrophils Hellewell PG, Williams TJ (eds) (London Academic Press Ltd) pp 295-314 
3. Cox G, Crossley J and Xing Z (1995) Macrophage engulfment of apoptotic neutrophils contributes to the resolution of pulmonary inflammation in vivo. Am. J. Respir. Cell. Mol. Biol. 12: 232-237

4. Haslett C, Savill JS, Whyte MK, Stern M, Dransfield I and Meagher LC (1994) Granulocyte apoptosis and the control of inflammation. Philo. Trans. R. Soc. Lond. B. Biol. Sci. 345: 327-333

5. Whyte MKB, Meagher LC, MacDermot $J$ and Haslett C (1993) Impairment of function in ageing neutrophils is associated with apoptosis. J. Immunol. 150: 5124-5134

6. Dransfield I, Stocks SC and Haslett C (1995) Regulation of cell adhesion molecule expression and function associated with neutrophil apoptosis. Blood 85: $3264-3273$

7. Savill JS, Fadok VA, Henson PM and Haslett C, (1993) Phagocyte recognition of cells undergoing apoptosis. Immunol. Today 14: 131-136

8. Fadok VA, Bratton DL, Konowal A, Freed PW, Westcott JY and Henson PM (1998) Macrophages that have ingested apoptotic cells in vitro inhibit proinflammatory cytokine production through autocrine/paracrine mechanisms involving TGF-beta, PGE2, and PAF. J. Clin. Invest. 101: 890-898

9. Verhoven B, Schlegel RA and Williamson P (1995) Mechanisms of phosphatidylserine exposure, a phagocyte recognition signal, on apoptotic $T$ lymphocytes. J. Exp. Med. 182: 1597-1601

10. Homburg $\mathrm{CHE}$, de Haas $M$, von dem Borne $A E G$, Verhoeven AJ, Reutelingsperger CPM and Roos D (1995) Human neutrophils lose their surface $\mathrm{Fc}(\mathrm{RIII})$ and acquire annexin $\mathrm{V}$ binding sites during apoptosis in vitro. Blood 85: $532-540$

11. Fadok VA, Voelker Dr, Campbell PA, Cohen JJ, Bratton DL and Henson PM (1992b) Exposure of phosphatidylserine on the surface of apoptotic lymphocytes triggers specific recognition and removal by macrophages. J. Immunol. 148: 2207-2216

12. Fadok VA, Savill JS, Haslett C, Bratton DL, Doherty D, Campbell PA and Henson PM (1992a) Different populations of macrophages use either the vitronectin receptor or the phosphatidylserine receptor to recognize and remove apoptotic cells. J. Immunol. 149: 4029-4035

13. Hart SP, Haslett C and Dransfield I (1996) Recognition of apoptotic cells by phagocytes. Experientia 52: 950-956

14. Moffatt OD, Devitt A, Bell ED, Simmons DL and Gregory CD (1999) Macrophage recognition of ICAM-3 on apoptotic leukocytes. J. Immunol. 162: 6800-6810

15. Platt N, da Silva R and Gordon S (1998) Recognizing death: the phagocytosis of apoptotic cells. Trends Cell Biol. 8: 365-372

16. Hart SP, Dougherty GJ, Haslett C and Dransfield I (1997) CD44 regulates phagocytosis of apoptotic neutrophil granulocytes, but not apoptotic lymphocytes, by human macrophages. J. Immunol. 159: 919-925

17. Devitt A, Moffatt OD, Raykundalia C, Capra JD, Simmons DL and Gregory CD (1998) Human CD14 mediates recognition and phagocytosis of apoptotic cells. Nature 392: 505-509

18. Botto M, Dell'Agnola C, Bygrave AE, Thompson EM, Cook HT, Petry F, Loos M, Pandolfi PP and Walport MJ (1998) Homozygous C1q deficiency causes glomerulonephritis associated with multiple apoptotic bodies. Nature Genetics 19: $56-59$

19. Schwartz BR, Karsan A, Bombeli T and Harlan JM (1999) A novel $\beta 1$ integrindependent mechanism of leukocyte adherence to apoptotic cells. J. Immunol. 162: $4842-4848$

20. Dransfield I, Buckle A-M, Savill JS, McDowall A, Haslett C and Hogg N (1994) Neutrophil apoptosis is associated with a reduction in CD16 (Fc $\gamma \mathrm{RIII})$ expression. J. Immunol. 153: $1254-1263$

21. Murray J, Barbara JAJ, Dunkley SA, Lopez AF, van Ostade X, Condliffe AM, Dransfield I, HaslettC and Chilvers ER (1997) Regulation of neutrophil apoptosis by tumor necrosis factor $\alpha$ : Requirement for TNFR55 and TNFR75 for induction of apoptosis in vitro. Blood 90: 2772-2783
22. Cosulich SC, Horiuchi H, Zerial M, Clarke PR and Woodman PG (1997) Cleavage of rabaptin- 5 blocks endosome fusion during apoptosis. EMBO J. 16: 6182-6191

23. Dini L, Autuori F, Lentini A, Oliverio S and Piacentini M (1992) The clearance of apoptotic cells in the liver is mediated by the asialoglycoprotein receptor. FEBS Lett. 296: $174-178$

24. Morris RG, Hargreaves AD, Duvall E andWyllie AH(1984)Hormone-induced cell death. 2. Surface changes in thymocytes undergoing apoptosis. Am. J. Pathol. 115: $426-436$

25. Stocks SC, Kerr MA, Haslett C and Dransfield I (1995) CD66-dependent neutrophil activation: a possible mechanism for vascular selectin-mediated regulation of neutrophil adhesion. J. Leukoc. Biol. 58: 40-48

26. Cross AS and WrightDG (1991) Mobilization of sialidase from intracellular stores to the surface of human neutrophils and its role in stimulated adhesion responses of these cells. J. Clin. Invest. 88: 2067-2076

27. O'Connell J, Haslett C and Dransfield I (1995) Rapidly modulated neutrophil antigens defined by myeloid panel mAb. In Leucocyte Typing V: White Cell Differentiation Antigens Schlossmann SF, Boumsell L, Gilks W, Harlan JM, Kishimoto T, Morimoto C, Ritz J, Shaw S, Silverstein R, Springer T, Tedder TF Todd RF eds (Oxford, Oxford University Press) pp. 1046-1048

28. Russell L, Waring P and Beaver JP (1998) Increased cell surface exposure of fucose residues is a late event in apoptosis. Biochem. Biophys. Res. Comm. 250 $449-453$

29. Stockton BM, Cheng G, Manjunath N, Ardman B and von Andrian UH (1998) Negative regulation of $T$ cell homing by CD43. Immunity 8: 373-381

30. Savill JS, Hogg N, Ren Y and Haslett C (1992) Thrombospondin cooperates with CD36 and the vitronectin receptor in macrophage recognition of neutrophils undergoing apoptosis. J. Clin. Invest. 90: 1513-1522

31. Dransfield I, Moir AJG, Sheth B, Burton DR and Partridge LJ (1988) Initial characterization of an anti-actin monoclonal antibody (NH3). Biochem. Soc. Trans. 16: 163-164

32. Newton RA and Hogg N (1998) The human S100 protein MRP-14 is a novel activator of the beta 2 integrin Mac-1 on neutrophils. J. Immunol. 160: 1427 1435

33. Edgeworth J, Gorman M, Bennett R, Freemont P and Hogg N (1991) Identification of p8,14 as a highly abundant heterodimeric calcium binding protein complex of myeloid cells. J. Biol. Chem. 266: 7706-7713

34. Shaw JO, Pinckard RN, Ferrigni KS, McManus LM and Hanahan DJ (1981) Activation of human neutrophils with 1-O-hexadecyl/octadecyl-2-acetyl-snglycerol-3-phosphorylcholine (platelet activating factor). J. Immunol. 127: $1250-1255$

35. Suchard SJ, Boxer LA and Dixit VM (1991) Activation of human neutrophils increases thrombospondin receptor expression. J. Immunol. 147: 651-659

36. Ackerman SK and Douglas SD (1978) Purification of human monocytes on microexudate-coated surfaces. J. Immunol. 120: 1372-1374

37. Partridge LJ and Dransfield I (1993) Isolation and characterization of mononuclear phagocytes. In: Tumor Immunobiology: a Practical Approach. Gallagher G, Rees RC, Reynolds CW eds (Oxford, UK, Oxford University Press) pp $91-118$

38. Lawler J and Hynes RO (1986) The structure of human thrombospondin, an adhesive glycoprotein with multiple calcium-binding sites and homologies with several different proteins. J. Cell Biol. 103: 1635-1648

39. Dhoot GK, Dransfield I, Grand RJ and Perry SV (1986) Distribution of isoforms of the myofibrillar proteins in myoid cells of thymus. J Muscle Res. Cell Motil. 7 : $351-360$ 